\title{
PENGHITUNGAN LUAS DAERAH DI DALAM KURVA POLAR
}

\author{
Rohadi Utomo $^{(1)}$, R. Gunawan Santosa ${ }^{(2)}$, Nugroho Agus Haryono ${ }^{(3)}$
}

\begin{abstract}
Abstrak:
Sistem Koordinat Polar dalam matematika adalah sistem koordinat dua dimensi yang mana setiap titik dalam bidang datar ditentukan oleh sebuah sudut $(\theta)$ dan sebuah jarak bertanda ( $r$ ). Kurva Polar. Fungsi Polar dapat dibuat dengan mendefinisikan $r$ sebagai fungsi dari $\theta$. Kurva yang dihasilkan dari penggambaran titik-titik yang memenuhi persamaan dalam bidang koordinat polar dinamakan Kurva Polar. Beberapa tipe kurva polar antara lain: limacon, lemniscate, rose curve, cardioid, dan spiral.

Pengitungan luas daerah di dalam kurva polar merupakan permasalahan matematika yang perlu diselesaikan. Perhitungan luas daerah tersebut dapat dilakukan secara analitik maupun secara numeris. Dalam Tulisan ini akan dibahas sebuah program yang telah dibuat untuk menyelesaikan perhitungan luas daerah di dalam kurva Polar secara komputasi numeris.

Dari hasil beberapa percobaan yang dilakukan terhadap beberapa fungsi polar yang diujikan, diperoleh hasil perhitungan luas secara komputasi numeris menggunakan porgram yang dibuat mendekati hasil yang dihitung menggunakan analitic dengan error mendekati nol.
\end{abstract}

Kata Kunci : Koordinat Polar, Luas Daerah, Luas Sektor.

\section{Pendahuluan}

Sistem Koordinat merupakan sebuah sistem untuk menentukan suatu titik dalam sebuah ruang $n$-dimensi. Sistem untuk satu-dimensi dinamakan dengan sistem garis bilangan, yaitu digunakan untuk menentukan posisi suatu bilangan. Sistem untuk dua-dimensi dinamakan dengan bidang datar, digunakan untuk menentukan pasangan dua titik $(a, b)$. Sistem Koordinat Polar termasuk dalam sistem yang digunakan untuk menentukan posisi suatu titik dalam bidang datar. Bidang yang menjadi tempat penyajian suatu titik dalam sistem koordinat polar dinamakan Bidang Polar.

Koordinat Polar banyak digunakan pada sitasi hubungan dua titik yang lebih mudah bila disajikan dalam bentuk sudut dan jarak. Sedangkan dalam Koordinat Kartesian atau Sistem Koordinat Persegi Panjang, biasanya relasi tersebut harus disajikan dalam bentuk Trigonometri. Kurva Polar mempunyai bentuk-bentuk yang menarik dengan kelengkungan yang halus. Penggambaran Kurva Polar secara manual membutuhkan ketelitian dan pengetahuan tentang sudut.

Salah satu permasalahan yang perlu dibahas dalam kurva polar adalah bagaimana penghitungan luas daerah di dalam kurva polar menggunakan komputasi numeris. Dalam tulisan ini disajikan program perhitungan luas daerah di dalam kurva polar.

\section{Koordinat Polar}

Koordinat Polar dibangun dengan menggunakan dua acuan, yaitu: satu titik pusat (pole) dan satu sumbu Kutub yang berupa garis mendatar dari titik pusat ( $x$-ray) ke arah kanan. Suatu titik dalam Bidang Polar disajikan dalam $\mathrm{P}(r, \theta)$ dengan $r$ menyatakan jarak bertanda (assigned distance) dari titik pusat ke titik $P$, dan $\theta$ menyatakan besarnya sudut yang diukur dari sumbu Kutub ke arah sumbu yang menghubungkan titik pusat dengan titik $P$. Sudut $\theta$ bernilai positif jika diukur berlawanan arah dengan perputaran jarum jam, dan bernilai negatif jika diukur searah dengan jarum jam. Titik ujung sudut adalah titik akhir sudut yang dibuat dari sumbu Kutub utama

\footnotetext{
(I) Rohadi Utomo, Alumni Program Studi Teknik Informatika Fakiltas Teknik Universitas Kristen Duta Wacana. Email : rohadi.it@gmail.com

(2) Drs. R. Gunawan Santosa, M.Si., Dosen Teknik Informatika Fakiltas Teknik Universitas Kristen Duta Wacana.

(3) Nugroho Agus Haryono, S.Si., M.Si., Dosen Teknik Informatika Fakiltas Teknik Universitas Kristen Duta Wacana.
} 
ke sumbu kutub P. Jarak $r$ bernilai positip jika diukur dari titik pusat menuju/mendekati titik ujung sudut, dan bernilai negaatif jika diukur dari titik pusat meninggalkan/menjauhi titik sudut. Penyajian titik $\mathrm{P}(r, \theta)$ dalam bidang Polar diberikan dalam Gambar 1. Sumbu-sumbu yang menyatakan besar sudut-sudut utama yang diwakili diberikan dalam Gambar 2.

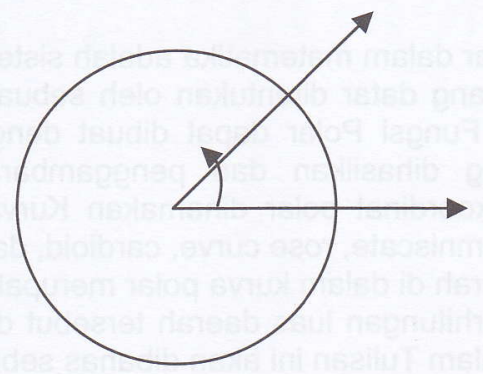

Gambar 1. Titik pada Koordunat Kutub (Polar)

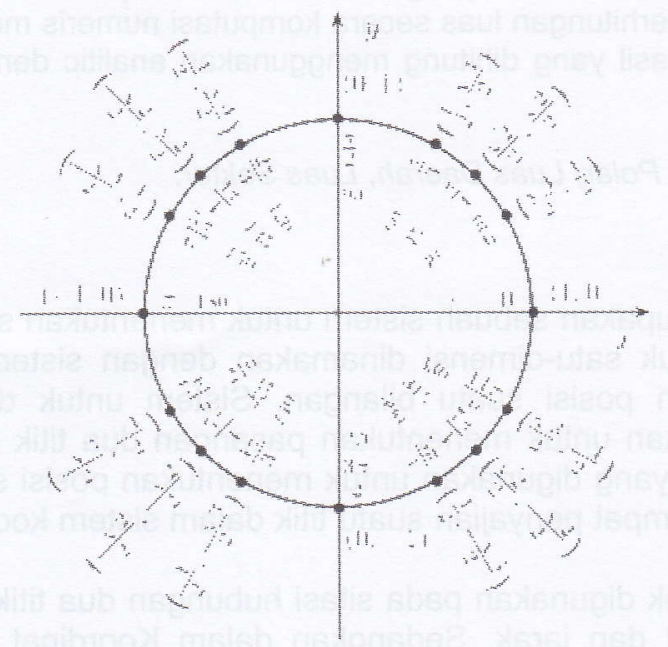

Gambar 2. Satuan sudut pada Koordunat Kutub (Polar)

Contoh penggambaran titik polar $\mathrm{P}\left(4, \frac{-\frac{\sqrt{3}}{3}}{\mathrm{st}}\right)$ diberikan dalam Gambar 3.

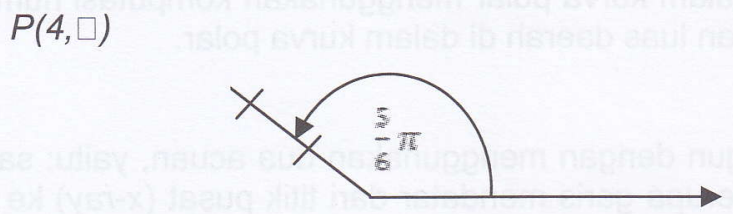

Gambar 3. Penggambaran titik pada koordinat polar

Untuk menggambar sebuah kurva polar sebuah persamaan polar $r=f(\theta)$ perlu terlebih dahulu dibuat tabel bantuan yang berisi pasangan $r$ dengan $\theta$. Misalkan akan dibuat kurva polar $r$ $=1-2 \cos \theta$, terlebih dahulu dibuat Tabel 1 untuk yang berisi pasangan $r$ dengan $\theta$. 
Tabel 1. Tabel persamaan $r=1-2 \cos \theta$.

\begin{tabular}{|l|l|l|l|l|}
\hline$\theta$ & $r$ & & & \\
\hline 0 & -1 & & $\pi+\frac{1}{6} \pi$ & $1+\sqrt{3}$ \\
\hline$\frac{1}{6} \pi$ & $1-\sqrt{3}$ & & $\pi+\frac{1}{3} \pi$ & 2 \\
\hline$\frac{1}{3} \pi$ & 0 & & $\pi+\frac{1}{2} \pi$ & 1 \\
\hline$\frac{1}{2} \pi$ & 1 & & $\pi+\frac{2}{3} \pi$ & 0 \\
\hline$\frac{2}{3} \pi$ & 2 & & $\pi+\frac{3}{6} \pi$ & $1-\sqrt{3}$ \\
\hline$\frac{5}{6} \pi$ & $1+\sqrt{3}$ & & $2 \pi$ & 3 \\
\hline$\pi$ & 3 & & & \\
\hline
\end{tabular}

Setelah kita dapat nilai-nilai tersebut maka selanjutnya setiap pasangan $r$ dengan $\theta$ diplot pada bidang polar dan dihubungkan sehingga diperoleh kurva seperti pada Gambar 4.

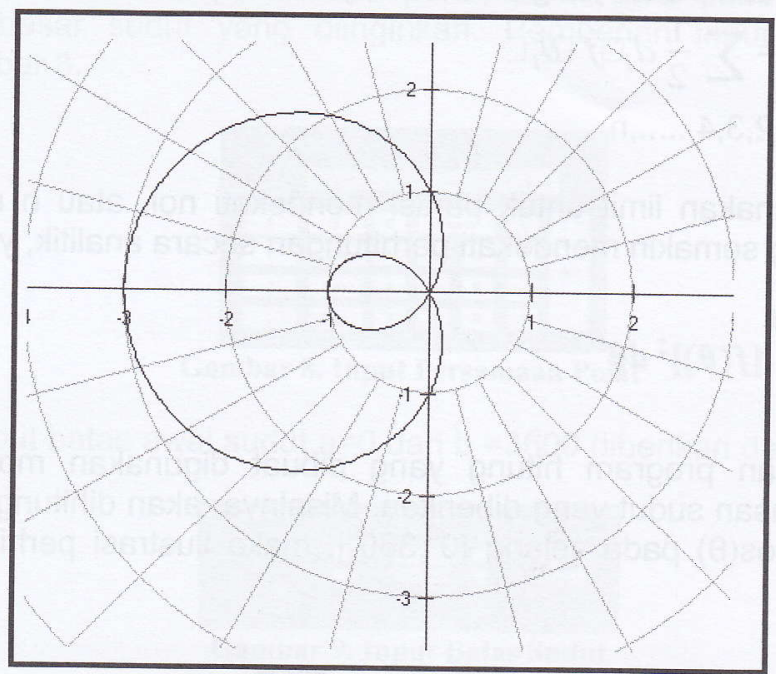

Gambar 4. Gambar kurva $r=1-2 \cos \theta$.

\section{Luas Daerah Di dalam Kurva Polar}

Perhitungan luas daerah di dalam kurva polar secara komputasi numeris dilakukan dengan menggunakan pendekatan luas juring-juring lingkaran hasil partisi yang dilakukan. Luas Juring lingkaran $(\mathrm{L})$ dengan besar sudut $\theta$ seperti pada Gambar 6 diberikan oleh :

$$
\begin{aligned}
& L=(\theta / 2 \pi) \pi r^{2}=\frac{1}{2} \theta r^{2}, \text { dengan } \\
& r=\text { jari-jari lingkaran } \\
& \theta=\text { besar sudut juring lingkaran }
\end{aligned}
$$




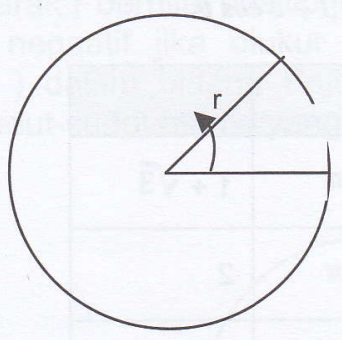

Luas Juring: $A=\frac{2}{2} \theta r^{2}$

Gambar 5. Penggambaran luas sektor lingkaran

Perhitungan luas kurva di dalam kurva polar dilakukan dengan langkah-langkah berikut ini.

1. Tentukan input yang berupa: persamaan polar $r=f(\theta)$, sudut awal: $\theta=\alpha$, dan sudut akhir: $\theta=\beta$, dengan $f$ kontinu dan non negatif pada selang tertutup $[\alpha, \beta]$.

2. Dilakukan partisi terhadap selang $[\alpha, \beta]$ menjadi $n$ bagian/partisi, sebagai berikut: $a=\theta_{0}<\theta_{1}<\theta_{2}<\cdots<\theta_{i-1}<\theta_{1}<\ldots<\theta_{n-1}<\theta_{n}=\beta$, dalam hal ini diambil besar sudut partis seragam, artinya $d_{i}=\theta_{i+1}-\theta_{i}$ sama untuk semua $i$. Diperoleh luas juring ke-i diberikan oleh :

$$
A_{i}=\frac{1}{2} d_{i} \square f \theta_{i} \sqsubset
$$

3. Diperoleh luas daerah yang dicari adalah sama didekati dengan jumlahan semua juring yang dibangun dari partisi yang dilakukan, yaitu:

$$
\begin{aligned}
& A=\sum A_{i}=\sum \frac{1}{2} d_{i} \square f \theta_{i} \sqsubset \\
& \text { untuk i }=1,2,3,4, \ldots ., \mathrm{n}
\end{aligned}
$$

Dengan menggunakan limit untuk partisi mendekati nol, atau $\mathrm{n}$ mendekati tak hingga akan diperoleh hasil yang semakin mendekati perhitungan secara analitik, yaitu :

$$
\left.A=\frac{1}{2} \int_{a}^{\theta} U(\theta)\right]^{2} d \theta
$$

Dalam pengerjaan program hitung yang dibuat digunakan model perhitungan luas disesuaikan dengan batasan sudut yang diberikan. Misalnya, akan dihitung luas daerah di dalam kurva polar $r=1+4 \cos (\theta)$ pada selang $\left[0^{\circ}, 360^{\circ}\right]$, maka ilustrasi perhitungan luas diberikan dalam Gambar 6.
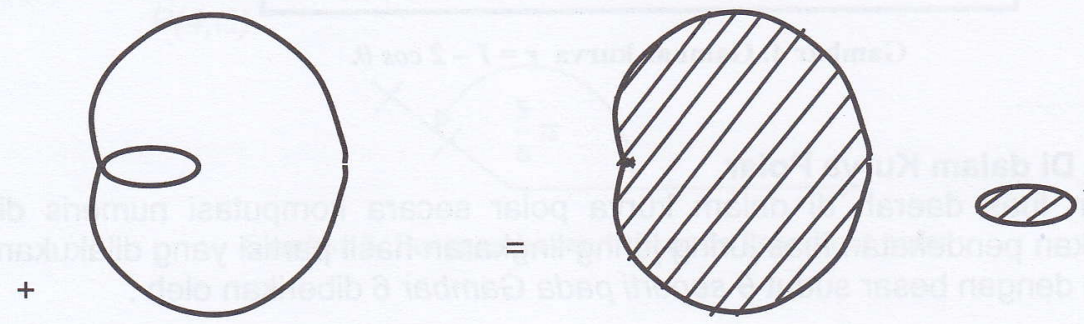

Gambar 6. Ilustrasi Perhitungan Luas

\section{Penghitungan Dengan Program}

Dengan menggunakan perhitungan numeris disusun program perhitungan luas daerah di dalam kurva polar seperti disajikan dalam Gambar 7 


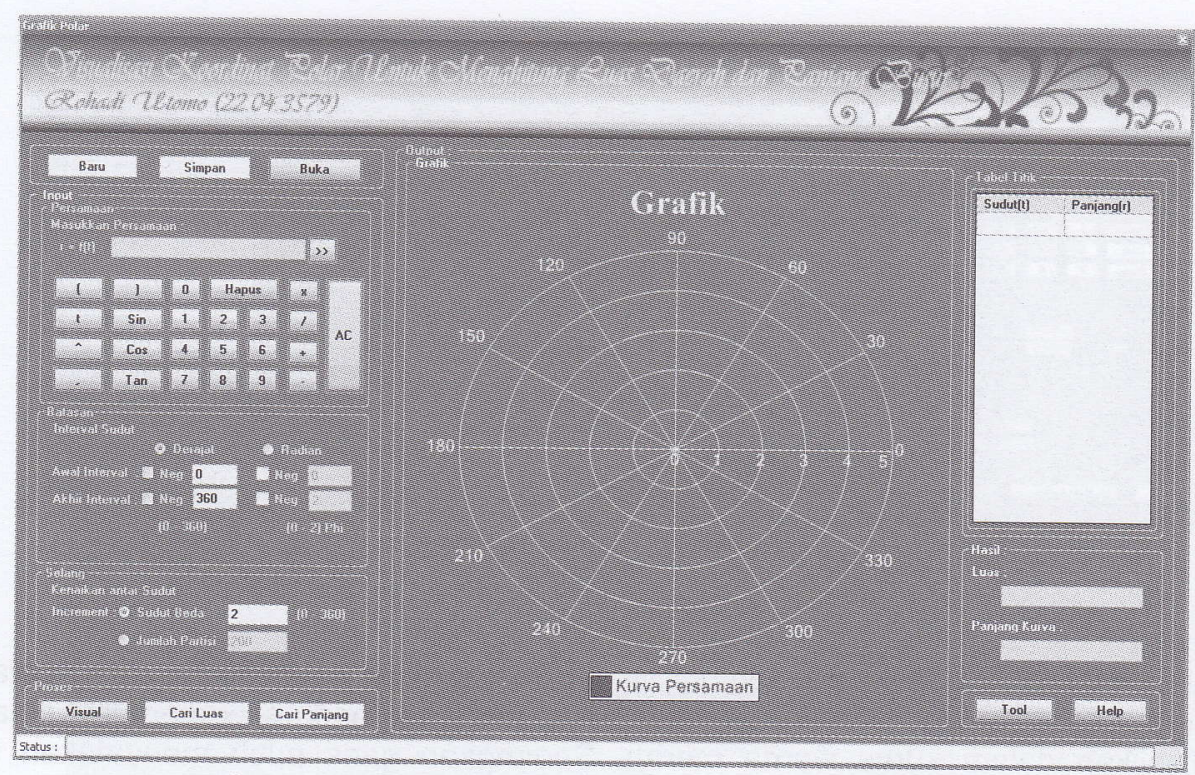

Gambar 7. Program Perhitungan Luas di dalam Kurva Polar

\subsection{Input}

Input program terdiri dari persamaan polar, batas awal sudut, batas akhir sudut dan jumlah partisi atau besar sudut yang diinginkan. Pemberian input persamaan $r=2+\operatorname{Cos}(\theta)$ diberikan dalam Gambar 8.

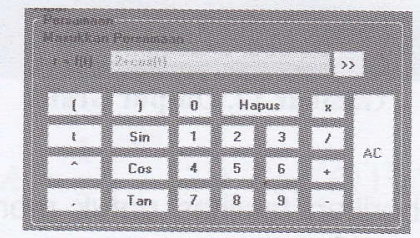

Gambar 8. Input Persamaan Polar

Pemberian input batas awal sudut $a=0$ dan $b=3600$ diberikan dalam Gambar 9 .

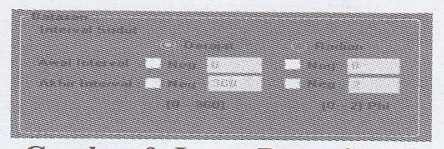

Gambar 9. Input Batas Sudut

Pemberian input jumlah partisi yang diinginkan n=100 diberikan dalam Gambar 10.

Gambar 10. Input Jumlah Partisi

\subsection{Proses}

Setelah semua input diisikan dengan benar, dilanjutkan dengan penekanan tombol proses yang meliputi visual untuk melihat visualisasi kurva polar yang diminta, cari luas untuk menghitung luas, dan cari panjang yang digunakan untuk menghitung panjang kurva sebagai fasilitas tambahan dalam program ini. Tombol proses diberikan dalam Gambar 11. 


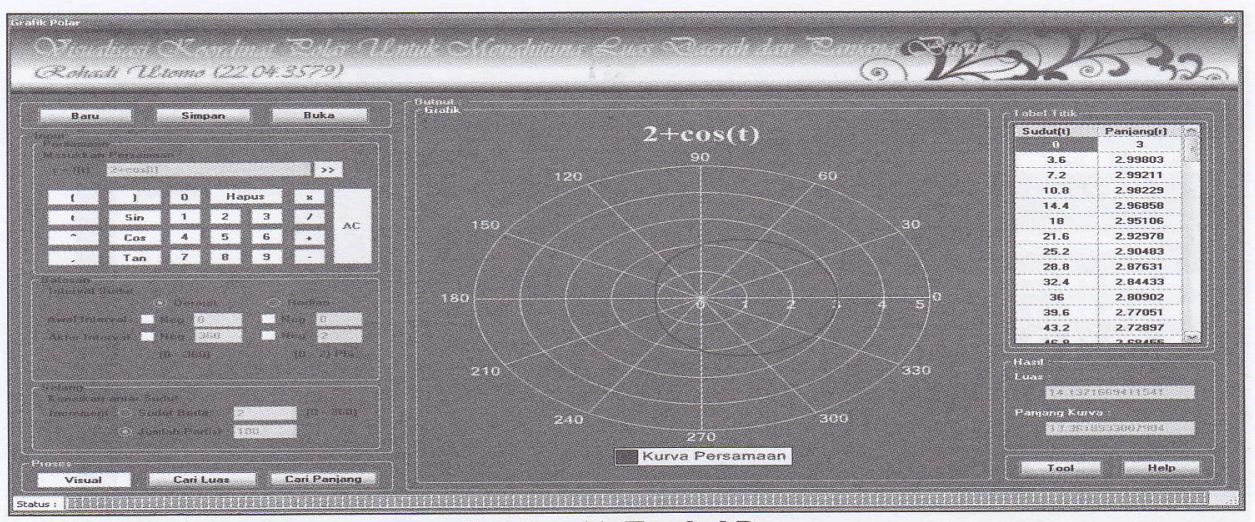

Gambar 11. Tombol Proses

\subsection{Output}

Setelah dilakukan penekanan tombol visual, maka akan ditampilkan kurva polar yang diminta, seperti pada Gambar 12. Kurva Polar yang menggambarkan persamaan polar yang diinputkan disajikan dalam kurva warna merah. Sedangkan garis putih menyatakan sumbusumbu yang diperlukan untuk memperjelas posisi titik.

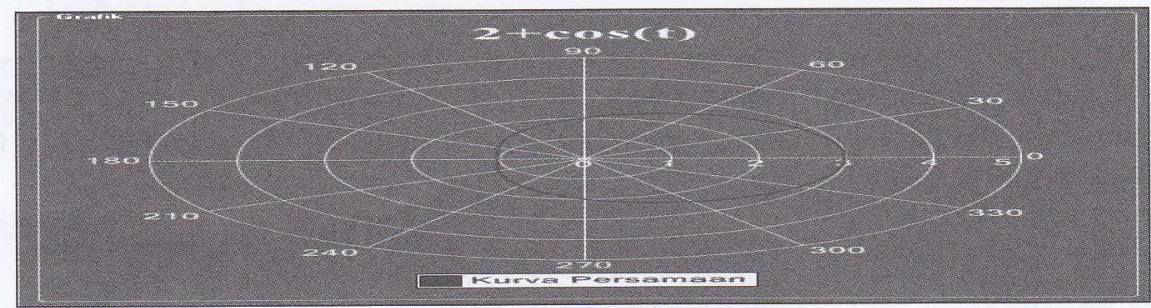

Gambar 12. Output Grafik

Dalam program ini juga diberikan fasilitas untuk mengetahui tabel pasangan sudut (t) dengan jarak (r), seperti pada Gambar 13.

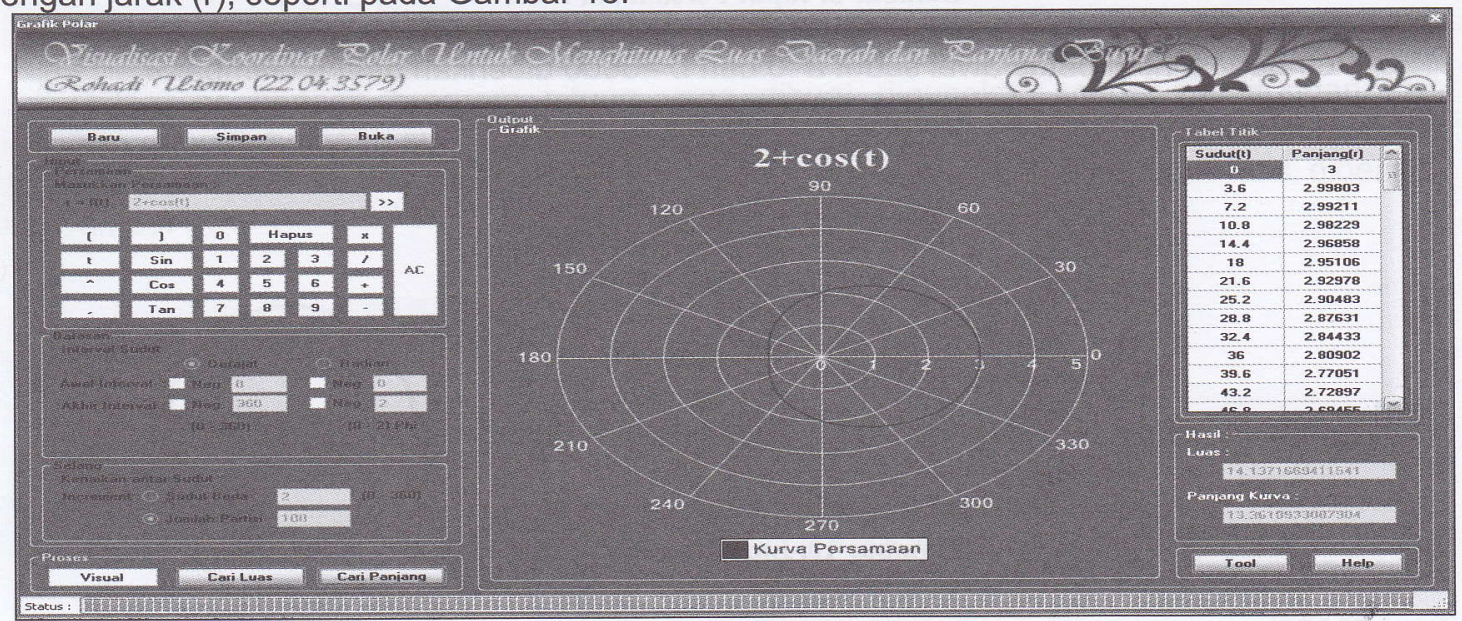

Gambar 13. Tabel Pasangan titik $(r, t)$

Hasil perhitungan luas di dalam kurva polar diberikan dalam Gambar 14. 


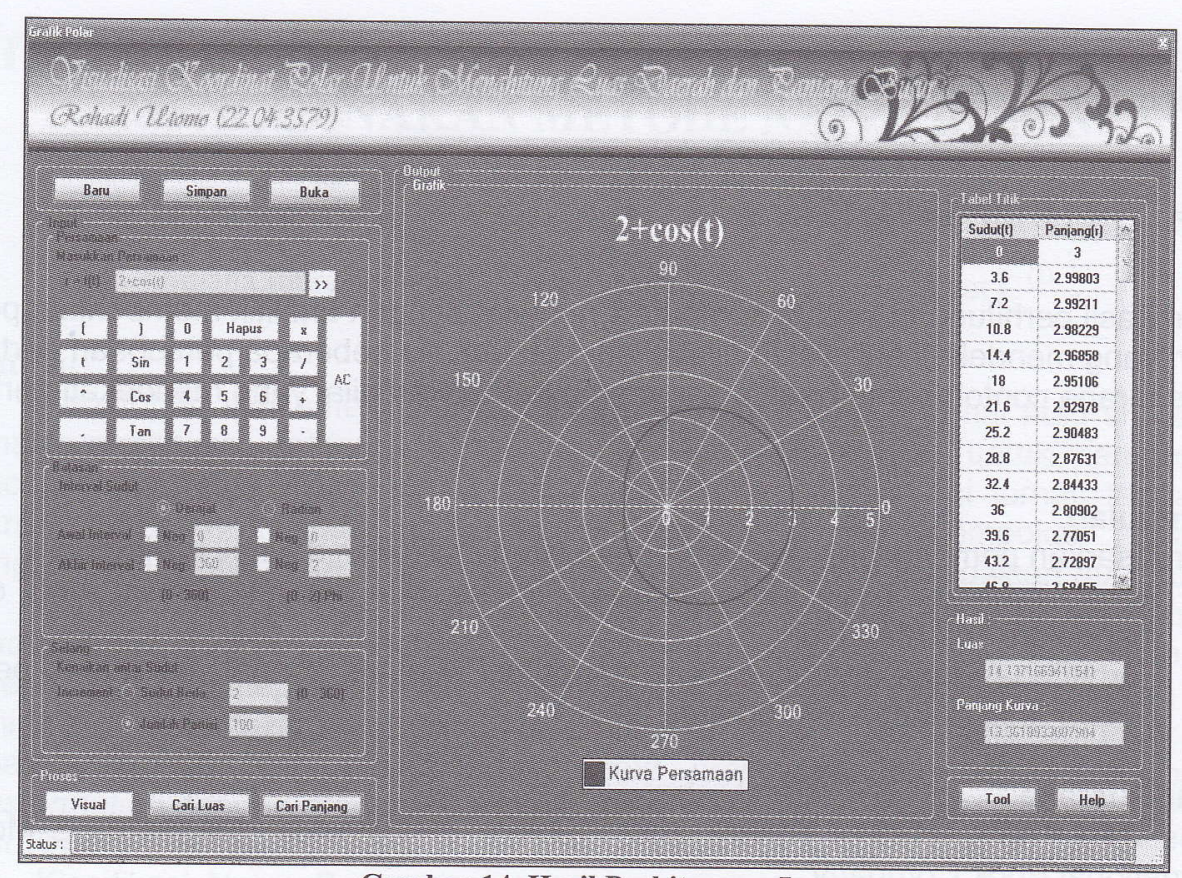

Gambar 14. Hasil Perhitungan Luas.

Jadi diperoleh luas daerah di dalam kurva polar $r=2+\cos (t)$, pada selan dengan jumlah partisi $n=100$ adalah: $A=14.1371669411541$

\section{Perhitungan Analitik}

Perhitungan analitik untuk luas daerah di dalam kurva polar $r=2+\operatorname{Cos}(\theta)$ pada selang
$\left[0^{\circ}, 360^{\circ}\right]$ diberikan oleh:

$$
A=\frac{1}{2} \int_{0}^{2 \pi}(2+\cos (\theta))^{2} d \theta
$$

Karena fungsi cosinus merupakan fungsi genap, maka hanya perlu dilakukan perhitungan untuk daerah dengan sudut $0 \leq 6 \leq \pi$, kemudian hasilnya dikalikan dengan 2 , sehingga diperoleh:

$$
\begin{aligned}
A & =\int_{0}^{\pi}(2+\cos (\theta))^{2} d \theta \\
& =\int_{0}^{\pi}\left(4+4 \cos (\theta)+\cos ^{2}(\theta)\right) d \theta \\
& =\int_{0}^{\pi} 4 d \theta+4 \int_{0}^{\pi} \cos \theta d \theta+\frac{1}{2} \int_{0}^{\pi}(1+\cos 2 \theta) d \theta \\
& =\int_{0}^{\pi} 4 d \theta+4 \int_{0}^{\pi} \cos \theta d \theta+\int_{0}^{\pi} \frac{1}{2} d \theta+\frac{1}{4} \int_{0}^{\pi}(\cos 2 \theta) d \theta \\
& =\left[4 \theta+4 \sin \theta+\frac{1}{2}-\frac{1}{4} \sin (2 \theta)\right]_{0}^{\pi} \\
& =\left[4 \pi+0+\frac{\pi}{2}-0\right]-[0+0+0-0] \\
& =4 \pi+\frac{\pi}{2} \\
& =\frac{9 \pi}{2}
\end{aligned}
$$


Jadi diperoleh luas daerah di dalam kurva polar yang diminta adalah

$$
A=\frac{9 \pi}{2}=14.1371669411541
$$

Dari hasil perhitungan secara komputasi numeris dengan analitik memberikan perbedaan perhitungan yang mendekati nol. Telah dilakukan oleh penulis beberapa percobaan perhitungan terhadap beberapa contoh persamaan polar yang memberikan nilai yang mendekati perhitungan analitik.

\section{Kesimpulan}

Berdasarkan pembahasan dan percobaan yang dilakukan diambil kesimpulan

a. Penggambaran kurva polar semakin halus jika jumlah partisi yang diinputkan mendekati 100 atau lebih.

b. Perhitungan luas daerah secara komputasi numeris sangat mendekati perhitungan secara analitik untuk $n=100$ atau lebih.

\section{Daftar Pustaka}

[1] Ayres J.P. Frank. (1981) Theory and Problem of Calculus. Singapore : McGraw-Hill International Book Company.

[2] Edwin J. Purcell, Dale Varberg. (1990) KALKULUS dan Geometri Analisis. Bandung : P.T. Gelora Aksara Pratama.

[3] Kaplan Wilfred, Lewis D.J. (1971) Calculus and Linear Algera New York : John Wiley \& Sons, Inc.

[4] Leithold Louis. (1988) Kalkulus dan Ilmu Ukur Analitik. Jakarta : Penerbit Erlangga

[5] Ratti J.S. (1981) Elementary Applied Calculus. University of South Florida : Meriner Publishing Company, Inc.

[6] Ross L. Finney, Franklin D. Demana, Bert K. Waits, Danil Kennedy. (2000) Calculus A Complete Course. USA : Addison Wesley Longman, Inc. 